\title{
DETERMINAÇÃO DOS ASPECTOS MORFOLÓGICOS DO SOLO E DENDROLÓGICOS DA VEGETAÇÃO EM UMA TOPOSSEQUÊNCIA, EM ALTAMIRA-PA
}

Gustavo Carvalho Spanner ${ }^{1}$, Émerson Santos das Neves ${ }^{1}$, Jarlisson Coelho do Nascimento ${ }^{1}$, João Alberto Costa Miléo ${ }^{1}$, Sandra Andréa Santos da Silva ${ }^{2}$.

${ }^{1}$ Graduandos do Curso de Engenharia Florestal, da Universidade Federal do PARA - UFPA, Campus de Altamira.

${ }^{2}$ Prof ${ }^{a}$ Doutora, Adjunto II, da Universidade Federal do PARA - UFPA, Campus de Tucuruí. E-mail: sandrasilva@ufpa.br

Recebido em: 05/12/2014 - Aprovado em: 14/12/2014 - Publicado em: 15/12/2014

\section{RESUMO}

O conhecimento a cerca de como se comporta a vegetação natural em diferentes ambientes pode dar auxílio em projetos que visem a conservação da biodiversidade local, além de contribuir em projetos de restauração florestal. Nesse contexto foi executado um estudo visando à correlação da vegetação com o relevo em uma topossequência, analisando características macromorfológicas dos aspectos físicos das árvores e a morfologia do solo (cor e textura), para isso, foram delimitadas quatro parcelas de $20 \times 40 \mathrm{~m}$, onde foram inventariados todos os indivíduos com Circunferência a 1,30m Acima do Peito $\geq 30 \mathrm{~cm}-$ CAP e analisado as características dendrológicas. Em cada ponto da parcela foi feita uma tradagem de 0 a $100 \mathrm{~cm}$ do solo analisando a cor com o auxilio da carta de Munsel e textura pela metodologia de Norticlif. Foi constatado que o fuste do tipo reto estava correlacionado com o decréscimo da altitude, no qual o número de árvores com essa característica diminuía juntamente com a característica dilatada. Em contrapartida, ocorria o inverso com a base do fuste tipo digitada, pois esta aumentava sua freqüência em relação ao decréscimo de altitude, essas começaram a surgir a partir da parcela três, onde começou a ocorrer uma considerável mudança da altitude, conseqüentemente aumentando a sua freqüência na parcela quatro. Para todos os pontos coletados não houve diferença na textura, todos foram do tipo "franco". A cor Bronw predominou em todos os pontos. Constatou-se que a vegetação segue padrões em ambientes onde o relevo é acidentado.

PALAVRAS-CHAVE: Aspectos macromorfológicos. Mecanismos adaptativos. Vegetação-relevo.

\section{MORPHOLOGIC CHARACTERISTICS AND DENDROLOGICAL ASPECTS OF VEGETATION IN A TOPOSSEQUENCE, IN ALTAMIRA-PA.}

\begin{abstract}
The knowledge over how natural vegetation behaves in different environments might give support on local biodiversity conservation projects, in addition to contributing for forest restoration. In this context, a study about a topossequence, correlation between vegetation and relief was executed, analyzing macromorphologic characteristics of physical aspects of trees and the morphology of the soil (color and
\end{abstract}


texture), for that matter, 4 (four) plots of $20 \times 10 \mathrm{~m}$ were delimitated, where all the individuals with circumference $1,30 \mathrm{~m}$ above the breast $\geq 30 \mathrm{~cm}-$ CAP and analyzed dendrological characteristics. On each point of the plot a borehole of 0 to $100 \mathrm{~cm}$ of soil, analyzing the color with the support of Munssel's and texture by Noticlif's methodology. Evidence shows that the straight type shaft was related to the decrease of height, which the number of trees with this characteristic decreased along with the dilated. In return, the inverse occurred with the typed-kind shaft, as this one increased its frequency in relation to the decrease in height. This changes started to come up from plot three, where a considerable height change started to occur, causing increase on its frequency on plot four. For all points collected there were no difference in texture, they were all loam type. And brown was the color that ruled over in all points. It showed that vegetation follow standards in different environments where the relief is damaged.

KEYWORDS: Adaptive mechanisms. Relief-vegetation. Macromorphologic characteristics.

\section{INTRODUÇÃO}

As florestas nativas e a maioria dos ecossistemas tropicais apresentam grande heterogeneidade florística por ocuparem diferentes ambientes, a variação dos fatores ecológicos que compreendem as margens dos cursos d'água até as áreas altas (topos de morros e montanhas) resultam em uma vegetação arbustiva-arbórea adaptada a tais variações (MARTINS, 2010).

Ao se observar uma paisagem, o solo pode ser considerado um elemento secundário, sendo comparado ao relevo, à vegetação e à hidrologia. Entretanto, as características do solo como fertilidade, profundidade efetiva, capacidade de retenção de umidade e infiltração influem na organização das paisagens tal como elas se encontram no presente (ÁVILA, 2009).

O solo desempenha papel fundamental, pois interfere na formação e entendimento das paisagens, fornecendo suporte mecânico, água e nutrientes para o estabelecimento e desenvolvimento das plantas. O estudo do solo serve para melhorar o seu aproveitamento e conservação, tanto para a agricultura quanto para o meio ambiente (FERREIRA, 2007). O conhecimento do solo com a vegetação permite a melhor compreensão das condições naturais dos ecossistemas e assim é possível minimizar as possíveis conseqüências negativas durante os processos de intervenção do ambiente.

O estudo do solo, como as suas características de cor e textura são a base para planejamento de seu uso em atividades de recuperação de áreas degradadas, plantios comerciais e florestais, conforme estudos realizados por BISPO et al., (2009), o qual relata que pesquisas envolvendo o relevo e a vegetação são de grande importância para o entendimento da dinâmica e da formação da Floresta Amazônica. Vale ressaltar, que o relevo influencia os processos de formação dos solos, além de influir na drenagem interna e externa do solo, bem como modificando as condições microclimáticas locais onde o relevo se desenvolve (SIRTOLI, 2007).

As diferentes formas da paisagem expressa pelo relevo promovem variações nos atributos do solo em magnitudes diferenciadas, dependentes de um local especifico da paisagem (IPPOLITI et al., 2005). Essas variações estão correlacionadas com a fisiologia, fisionomia e ecologia da vegetação na paisagem.

O objetivo do trabalho foi analisar uma topossequência, localizada em AltamiraPA, quanto as suas características morfológicas do solo, correlacionando a variação de altitude com alguns aspectos físicos da vegetação. 


\section{MATERIAL E MÉTODOS}

O estudo foi realizado em uma propriedade localizada aproximadamente a $14 \mathrm{~km}$ do município de Altamira - PA, pertencente ao Sr. João Batista, sob as coordenadas Latitude: -03 11.34414' e Longitude: -52 10.75506' apresentando um fragmento da Floresta Amazônica. A área selecionada caracterizava-se por apresentar declives e uma vegetação de floresta Ombrofila Densa, com estádio de desenvolvimento caracterizada como secundária.

Segundo a classificação de Köppen o clima do município é do tipo equatorial Am e Aw. O primeiro, predominante na parte norte do município, apresenta temperaturas médias de $26^{\circ} \mathrm{C}$, e precipitação anual, girando em torno de $1.680 \mathrm{~mm}$, sendo que os meses mais chuvosos vão de dezembro a maio e, os menos chuvosos, de junho a novembro. O segundo ao sul é o Aw em virtude da extensão do município, passa por uma transição até alcançar o tipo savano (PARÁ, 2011).

A topossequência foi dividida em quatro parcelas amostrais de $20 \times 40 \mathrm{~m}$ (Figura 1). A escolha da forma retangular da parcela foi devido a amostragem representativa da área, pois o declínio se encontrava nas partes finais, sendo assim, representando todas as diferenças espaciais.

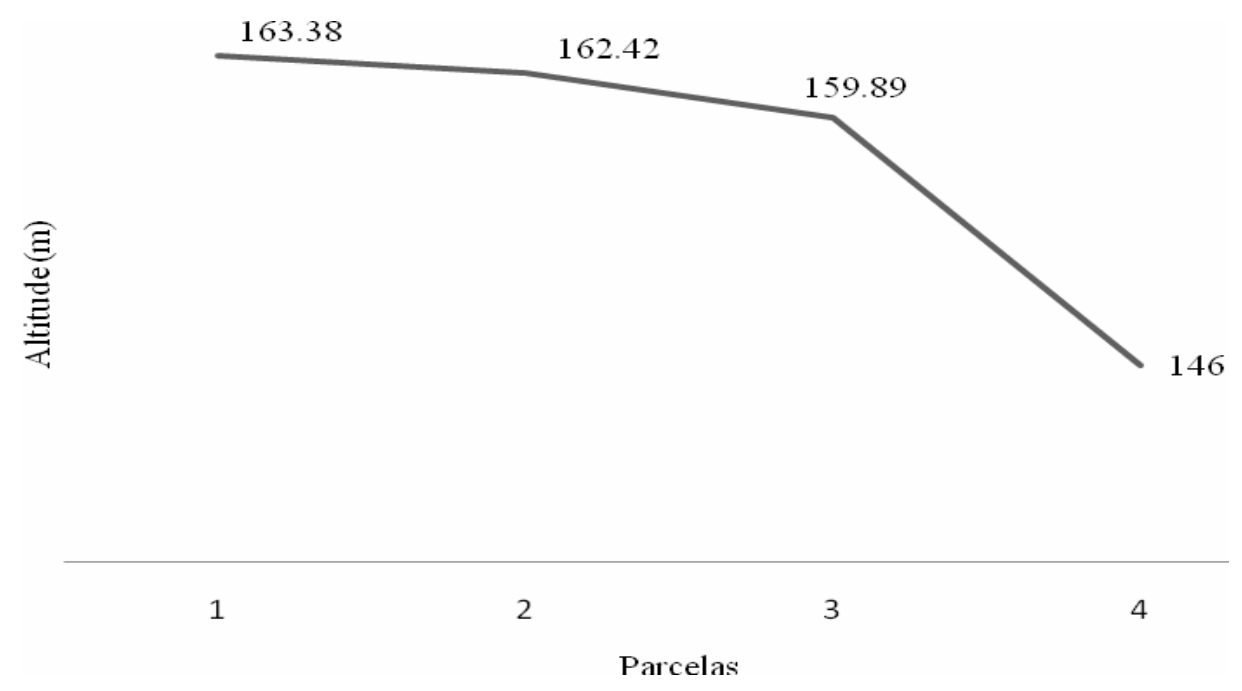

FIGURA 1. Representação do relevo em relação à altitude.

Para o levantamento das espécies arbóreas, dentro de cada subparcela, foram inventariados todos os indivíduos de Circunferência com 1,30 m Acima do Peito $\geq 30$ $\mathrm{cm}$ (CAP) com o auxilio de uma fita métrica e a altura total estimada. A partir dos CAP calculou-se o Diâmetro Acima de $1,30 \mathrm{~m}$ do Peito (DAP) de cada individuo. As coletas foram efetuadas no período de junho a julho de 2013. Sendo os parâmetros dos aspectos macromorfológicos relacionados com a estrutura física das espécies arbóreas foram descritos quanto ao tipo e forma do fuste e raízes. A análise dos dados foi feita pela estatística descritiva, utilizando o programa da Microsoft Excel 2007.

Nas coletas de tradagem do solo, os pontos selecionados correspondem ao ponto central de cada extremidade das subparcelas, totalizando cinco pontos na topossequência. As amostras foram coletadas com trado holandês e em cada ponto foi realizada a retirada de cinco amostras de $20 \mathrm{em} 20 \mathrm{~cm}$, sendo coletados até a 
profundidade de $100 \mathrm{~cm}$ em cada ponto. Depois de coletadas as amostras, as mesmas foram acondicionadas em sacos plásticos de um quilo devidamente protocolados e encaminhadas ao laboratório de Química da Faculdade de Engenharia Florestal, do Campus Universitário da Universidade Federal do Pará UFPA.

Os materiais utilizados para a realização do trabalho foram um trado de $20 \mathrm{~cm}$, trena, piquetes, placas de alumínio, martelo, pregos, fita zebrada, GPS, pranchetas, lápis, borracha, planilhas em branco, sacos plásticos, facões, prensa de $30 \times 40 \mathrm{~cm}$, barbante, jornais velhos, e fita centimétrica

As amostras de solos foram secadas, peneiradas (TFSA), sendo analisadas: a cor com o auxílio da carta de Munsell e a textura determinada através do fluxograma de Norticliff como proposto por ROWELL (1994).

\section{RESULTADOS E DISCUSSÕES}

Depois de analisadas cor e textura dos solos em laboratórios, observou-se que não existiu variação quanto a textura do solo, uma vez que a textura foi do tipo "franca" para todos os pontos coletados (Tabela 1). A textura se refere a proporções dos vários grupos de grãos individuais que formam o solo, principalmente ao conteúdo de argila, silte e areia. A textura "franca" é caracterizada como sendo o material do solo que contém de 7 a $27 \%$ de argila, de 28 a $50 \%$ de silte e menos de $52 \%$ de areia (VIEIRA, 1988).

TABELA 1. Características morfológicas do solo amostrado em todas as parcelas na área de estudo.

\begin{tabular}{|c|c|c|c|}
\hline $\begin{array}{l}\text { PROFUNDIDADE } \\
(\mathrm{cm})\end{array}$ & TEXTURA & COR & PORCENTAGEM \\
\hline \multirow{2}{*}{$0-20$} & \multirow{2}{*}{ Franco } & \multirow{2}{*}{$\begin{array}{c}\text { Brown } \\
\text { Reddish Brown } \\
\text { Very dark grayish } \\
\text { Brown } \\
\end{array}$} & $\begin{array}{l}72 \% \\
14 \%\end{array}$ \\
\hline & & & $14 \%$ \\
\hline $20-40$ & Franco & $\begin{array}{c}\text { Brown } \\
\text { Reddish Brown }\end{array}$ & $\begin{array}{l}86 \% \\
14 \% \\
\end{array}$ \\
\hline \multirow{3}{*}{$40-60$} & \multirow{3}{*}{ Franco } & Brown & $72 \%$ \\
\hline & & Reddish Brown & $14 \%$ \\
\hline & & Light Brown & $14 \%$ \\
\hline \multirow{3}{*}{$60-80$} & \multirow{3}{*}{ Franco } & Brown & $72 \%$ \\
\hline & & Light reddish Brown & $14 \%$ \\
\hline & & Light Brown & $14 \%$ \\
\hline \multirow{3}{*}{$80-100$} & \multirow{3}{*}{ Franco } & Brown & $57 \%$ \\
\hline & & Light Brown & $29 \%$ \\
\hline & & Pole Brown & $14 \%$ \\
\hline
\end{tabular}

Existem variações de solos de textura franca em relação ao nome, a denominação das outras classes de franco são baseadas no tipo de partícula mais freqüente no solo, por exemplo, quando se tem uma maior fração de areia, se denomina a textura do solo como franco arenosa. 
Quanto à cor ficou evidente que Brown foi a que predominou em todas as profundidades (Tabela 1). Segundo BOTELHO et al. (2006) a cor do solo é avaliada em campo pela comparação visual de amostras secas e úmidas utilizando-se a carta de Munsell para solos, observando se o matiz (comprimento de onda da luz), o valor (brilho ou tonalidade) e o croma (intensidade ou pureza da cor em relação ao cinza).

Uma vez que o solo é constituído de vários fatores que interferem na sua estrutura física e química, é preciso dar ênfase a cor do solo, que segundo (CAMPOS et al., 2003; BOTELHO et al., 2006) é uma característica que está relacionada com a presença de óxidos de ferro e matéria orgânica no solo, sendo os principais agentes responsáveis pela cor dos solos.

A cor é determinada por três fatores importantes: matéria orgânica, conteúdo de sílica e compostos de ferro, onde cada cor representa um indicativo para o solo. Cores escuras evidenciam presença de matéria orgânica. Cores vermelhas indicam a existência de hematita caracterizando boa drenagem e aeração do solo. Cores claras são causadas por várias substâncias como quartzo de minerais claros diagnosticando a diminuição de materiais corantes. Cores acinzentadas indicam condições redutoras e de drenagem pobre, enquanto que as amarelas são causadas pela goethita caracterizando condições de boa drenagem (VIEIRA, 1988).

$\mathrm{Na}$ tabela 1, observam-se dados de textura e cor em função das profundidades estudadas e com os seus respectivos valores percentuais. Diante disto verifica-se que em todas as profundidades a cor Brown foi a de maior porcentagem e que em todas as profundidades, exceto a de 20-40 cm apresentaram três cores.

$\mathrm{Na}$ figura 2, pegou-se todos os dados da profundidade inicial de 0 à $20 \mathrm{~cm}$ e tirou-se a porcentagem, e assim foi feito em todas as outras. "Brown" representa 7.5YR na carta de Munsell, seguida de suas variações no croma, que neste caso foram: $5 / 3,5 / 4,4 / 3$ e $5 / 2$.

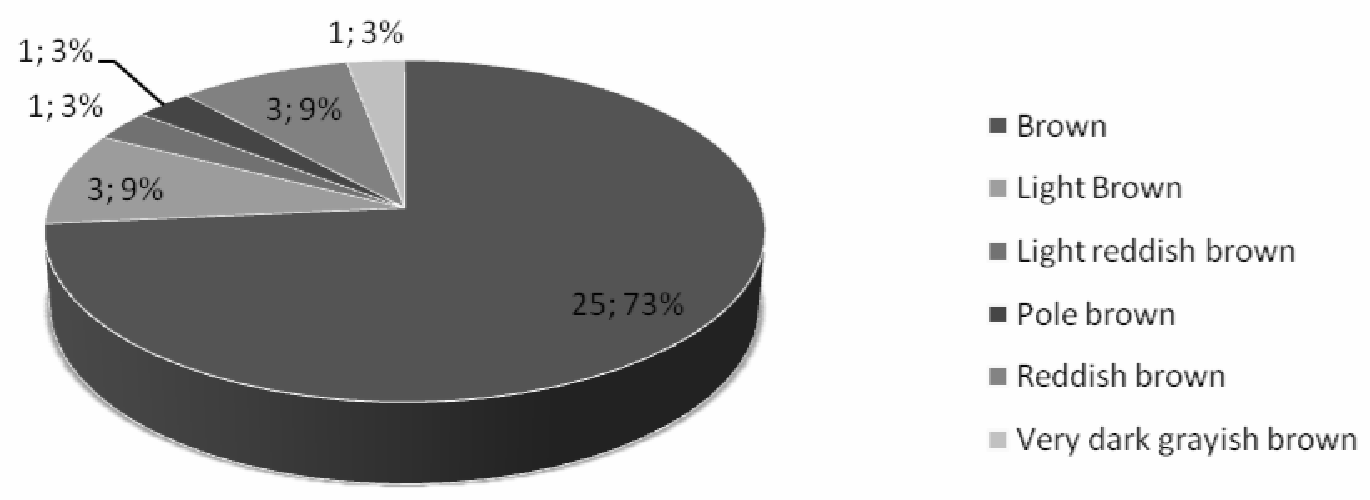

FIGURA 2. Porcentagem geral de cores da amostra unificada de solos.

A cor Reddish Brown, corresponde a 5YR com cromas 5/3 e 5/4; Very dark grayish brown representa 10YR e não apresentou variações de croma: 3/2; Light Brown é identificado por 7.5YR, e que também não apresentou variação no croma: 6/3; 5YR é a localização de Light reddish Brown na carta e de croma 6/3, e 10YR de 
Pole Brown, sem variação cromática: 6/3.

O fato de algumas cores não apresentarem variação quanto ao croma é devido só terem aparecido uma só vez em determinada profundidade. Light reddish Brown e Pole Brown, por exemplo, só ocorreram nas profundidades de $60 \mathrm{a} 80 \mathrm{~cm}$ e $80 \mathrm{a} 100 \mathrm{~cm}$ do primeiro ponto de coleta, e very dark grayish Brown apenas na primeira amostra $(0$ a $20 \mathrm{~cm})$ do quinto ponto de coleta.

A topografia está freqüentemente relacionada às variações físicas e químicas do solo que, muitas vezes, são refletidas pela vegetação (RODRIGUES et al., 2007), buscou-se conhecer esses padrões através dos aspectos dendrológicos. $\mathrm{Na}$ área estudada ficou evidente a relação das características dendrológicas com a variação de altitude. Compreender como as comunidades florestais se comportam em diferentes ambientes é fundamental para dar suporte ao planejamento que visa à exploração dos recursos naturais com base sustentável, além de ações que darão suporte a conservação desses ambientes.

Uma das características analisadas dendrologicamente foi à base do fuste, sendo este o aspecto que apresenta a porção do fuste logo acima do solo. Ela foi divida em três classes: Digitada, apresentando protuberâncias que se assemelham a dedos, Dilatada, quando a base do fuste apresentava um volume maior que todo o restante do fuste e Reta, com aspecto normal.

Foi observado que existe uma considerável correlação da base do fuste em relação à topografia. A característica que mais ficou evidente em relação à variação de altitude foi a retidão do fuste, que seguiu um padrão de declívio, quanto mais decrescia a altitude o número de árvores com essa característica diminuía juntamente com a característica dilatada, em oposição, ocorria o inverso com a base do fuste tipo Digitada, pois esta aumentava sua freqüência em relação ao decréscimo de altitude (Figura 3).
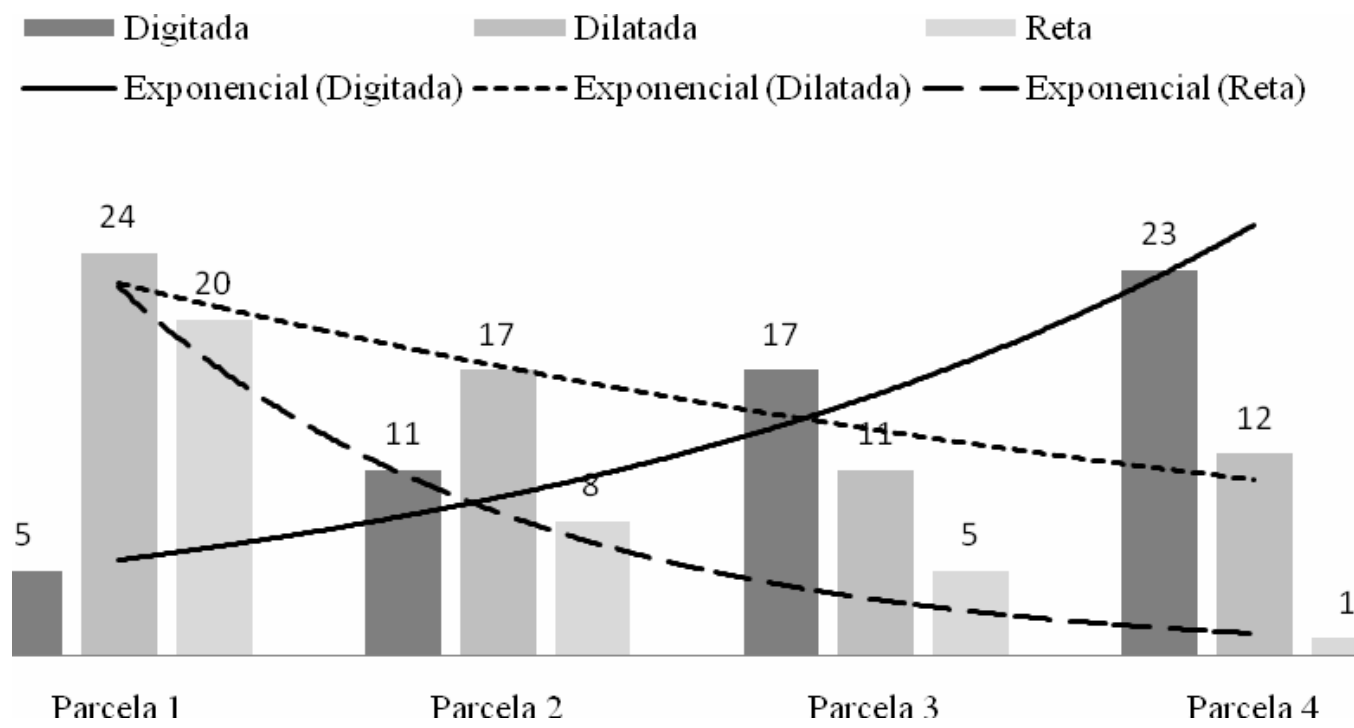

FIGURA 3. Amostragem da freqüência das características da base do fuste nas parcelas da topossequência.

Analisando os dados, percebeu-se que as classificações da base do fuste variavam de acordo com a localização das parcelas em ordem crescente, pois as mesmas seguiam um padrão de redução da altitude (Figura 1), acredita-se que 
esses padrões ocorrem devido ao relevo, então o relevo é um parâmetro da estrutura física das espécies vegetais no espaço e tempo, em escalas locais. Quanto mais inclinado for o terreno, mais necessário será que as espécies desenvolvam mecanismos para se manter no ambiente.

Corroborando com os padrões descritos anteriormente, pode-se fazer uma analogia usando a distribuição e frequência das classificações de raízes amostradas na área em relação às parcelas. Um ponto interessante a ser discutido é quanto às raízes do tipo tabulares, que segundo VIDAL \& VIDAL (2003) atingem grande desenvolvimento e tomam o aspecto de tábuas perpendiculares ao solo, essas começaram a surgir a partir da parcela três, onde começou a ocorrer uma considerável mudança da altitude, consequentemente aumentando a sua frequência na parcela quatro (Figura 4), fica evidente novamente que a vegetação cria mecanismos para ocupar ambientes diferenciados, sendo que talvez estes ambientais sejam mais limitados para as diversas espécies, então, as raízes tabulares segundo VIDAL \& VIDAL (2003) ampliam a base da planta, dando-Ihe maior estabilidade, sendo que nesses ambientes é de extrema importância ter características que melhore a sustentação das árvores, já que é um ambiente instável, segundo TURCl et al. (2006) esses tipos de raízes são comuns em espécies que ocorrem em solos instáveis e que sofrem influência das cheias durante um período do ano.

Seguindo o declívio, outra característica macromorfológica das espécies arbóreas que mudava eram as raízes superficiais, caracterizadas como sendo raízes grossas visíveis sobre o solo, com o passar das parcelas a freqüência de raízes superficiais decrescia. Em toda área amostrada houve apenas uma árvore que apresentou raiz do tipo adventícia, as raízes do tipo escoras não obedeceram a padrões de tendência (Figura 4).
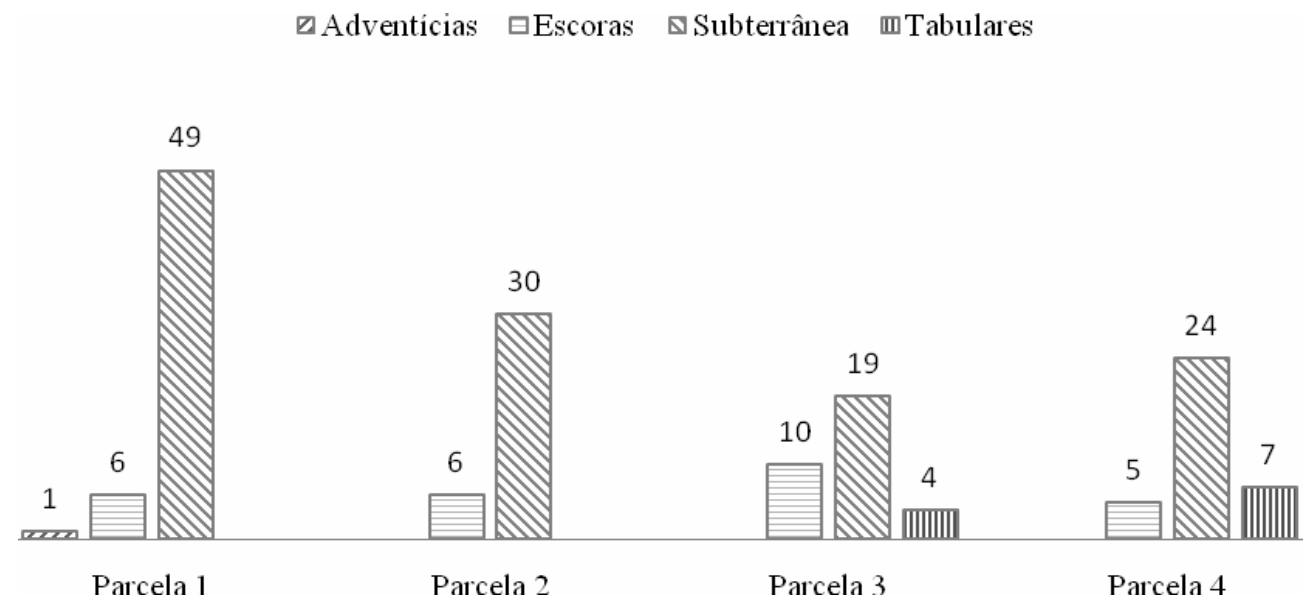

FIGURA 4. Amostragem da freqüência dos tipos de raízes da vegetação na topossequência.

Segundo CAMPOS (2009), estudando uma Ecótono Amazônia-Cerrado, a expressão da vegetação é reflexo das condições topográficas e do solo, pois a medida que o ocorria a elevação do terreno, a fisionomia ia mudando, cedendo lugar a uma formação de aspecto mais uniforme, dotada de árvores mais baixas, que constitui o "cerrado". 
Estudos realizado por BISPO et al., (2009) demonstraram que a elevação é um fator controlador referente à tipos de classes de vegetação, isso mostra que vários aspectos da paisagem estão relacionadas com o relevo e mudam conforme esse, comprovando isso, SANTOS et al., (2012), evidenciaram que a topografia exprime solos diferentes ao longo do relevo e que as mudanças deste interferem nos atributos do solo. CAMPOS et al., (2010) estudando uma topossequência em Manicoré - AM constataram que as variações do relevo favoreceram a presença de solos distróficos no topo alto e solos eutróficos no sopé de transporte.

BALIEIRO et al. (2008) evidenciaram que o relevo possui forte influência sobre a distribuição dos nutrientes ao longo de uma topossequência, concluindo que o relevo influencia fortemente nos atributos químicos do solo, corroborando com essa afirmação MEIRELES et al., (2012) constataram que a relação Fe livre/Fe total apresentou tendência de decrescimento em relação as parcelas implantadas ao longo de uma sequência topográfica, verificando ainda que algumas superfícies geomórficas situadas em diferentes posições no relevo diferem no grau de desenvolvimento da superfície. REIS et al., (2007) além de nutrientes, também provaram que ocorrem variações na constituição granulométrica e orgânica do solo.

Essas características relacionadas acabam resultando em ambientes heterogêneos. Para RODRIGUES et al., (2007) esses são resultados da diversidade de fatores que interagem nas comunidades e a resposta das espécies a esses fatores faz que cada local tenha características próprias e características que são comuns a outros locais, possibilitando observar tendências. Essas tendências podem responder a algumas perguntas e podem sugerir novas pesquisas contribuindo com novos conhecimentos.

Apesar de a área estudada ser de tamanho reduzido, ficaram evidenciados padrões de como a comunidade se comportava em relação ao relevo. Para MARTINS (2010), a grande variação topográfica e altitudinal no território brasileiro, com as mais variadas extensões e sob influência de uma ampla gama de variáveis ambientais, resultam em florestas variadas quanto a composição florística e estrutura fitossociológica, apesar de alguns padrões poderem ser identificados em escalas locais. E como resultado do estudo, é proposto que não só a composição florística e estrutura fitossociológica mudem em relação ao relevo, mas assim como também a estrutura física das espécies que compõem a comunidade.

\section{CONCLUSÃO}

Os resultados do estudo demonstram que não houve variação da textura do solo na topossequência estudada. Referente à cor, foi Brown que predominou em todas as profundidades.

Conclui-se que a vegetação está intimamente correlacionada com a paisagem em que está inserida. Foi possível descrever padrões de como se comporta aspectos físicos, como fuste e raízes, de espécies arbóreas em ambientes de topografia acidentada.

O conhecimento destes padrões poderá servir de base para a implementação de técnicas de conservação e restauração de ambientes que possuem essas particularidades.

\section{REFERÊNCIAS}

ÁVILA, F. F. Análise da cobertura pedológica em uma topossequência na Bacia do Córrego dos Pereiras - Depressão de Gouveia/MG. 2009. 125 f. Dissertação 
(Mestrado em Geografia) - Universidade Federal de Minas Gerais, Belo Horizonte, 2009.

BALIEIRO, F. C.; OLIVEIRA, W. C. O.; PEREIRA, M. G.; ANJOS, L. H. C.; PICCOLO, M. C.; JACCOUD, C. F. Fertilidade e carbono do solo e uso da água pelo eucalipto numa topossequência em Seropédica, RJ. Revista Árvore, v.32, n.1, p.153-162, 2008.

BISPO, P. C.; VALERIANO, M. M.; KUPLICH T. M. Variáveis geomorfométricas locais e sua relação com a vegetação da região de interflúvio Madeira - Purus (AM RO). Acta amazônica, v. 39, n. 1, p. 81 - 90, 2009.

BOTELHO, M. R.; DALMOLIN, R. S. D.; PEDRON, F. A.; AZEVEDO, A. C.; RODRIGUES, R. B.; MIGUEL, P. Medida da cor em solos do Rio Grande do Sul com a carta de Munssel e por colorimetria. Ciência Rural, v.36, n.4, p.1179-1185, 2006.

CAMPOS, R. C.; DEMATTÊ, J. A. M.; QUARTAROLI, C. F. Determinação do teor de hematita no solo a partir de dados de calorimetria e radiometria. Pesquisa Agropecuária Brasileira, v. 38, n. 4, p. 521-528, 2003.

CAMPOS, M. C. C.; RIBEIRO, M. R.; SOUSA JÚNIOR, V. S.; RIBEIRO FILHO, M. R.; COSTA, E. U. C. Segmentos de vertente e atributos do solo de uma topossequência na região de Manicoré, AM. Revista Ciência Agronômica, v. 41, n. 4, p. 501-510, 2010.

FERREIRA, I. C. M. Associações entre solos e remanescentes de vegetação nativa em Campinas. 2007. 107 f. Dissertação (Mestrado em Agricultura Tropical e Subtropical) - Instituto Agronômico, Campinas, 2007.

IPPOLITI, G. A. R.; COSTA, L. M.; SCHAEFER, C. E. G. R.; FERNANDES FILHO, E. I.; GAGGERO, M. R. Análise digital do terreno: ferramenta na identificação de pedoformas em microbacia na região de "Mar de Morros" (MG). Revista Brasileira de Ciência do Solo, v. 29, n. 02, p. 269-276, 2005.

MARTINS, S. V. Restauração florestal em áreas de preservação permanente e reserva legal. Viçosa: CPT, 2010. 316p.

MEIRELES, H. T.; JÚNIOR, J. M.; CAMPOS, M. C. C.; PEREIRA, G. T. Relação solo-paisagem em topossequência de origem basáltica. Pesq. Agropec. Trop., Goiânia, v. 42, n. 2, p. 129-136, 2012.

PARÁ. Estatística Municipal de Altamira. Instituto de Desenvolvimento Econômico, Social e Ambiental do Pará, 2011.

REIS, M. S.; FERNANDES, A. R.; GRIMALDI, C.; SARRAZIN, M.; GRIMALDI, M. Variação da composição granulométrica e orgânica do solo em uma topossequência da microrregião de Marabá-PA. Bol. Mus. Para. Emílio Goeldi. Ciências Naturais, v. 2, n. 3, p. 33-44, 2007.

RODRIGUES, L. A.; CARVALHO, D. A.; OLIVEIRA FILHO, A. T.; CURI, N. Efeitos de solos e topografia sobre a distribuição de espécies arbóreas em um fragmento de 
floresta estacional semidecidual, em Luminárias, MG. Revista Árvore, v.31, n.1, p.25-35, 2007.

ROWELL, D. L. Soil Science - Methods and aplications. England longman apoup IK, 1994.

SANTOS, L. A. C.; CAMPOS, M. C. C.; COSTA, H. S.; PEREIRA, A. R. Caracterização de solos em uma topossequência sob terraços aluviais na região do médio rio Madeira (AM). Revista Ambiência, v.8, n.2, p. 319 - 331, 2012.

SIRTOLI, A. E. O solo na paisagem. In: LIMA, V. C.; LIMA, M. R.; MELO, V. F. O solo no meio ambiente: abordagem para professores de ensino fundamental e médio e alunos do ensino médio. 1. ed. Universidade Federal do Paraná. Departamento de solos e Engenharia Agrícola. Curitiba, 2007.

TURCI, L. C. B., AlBuqueRQUE, S., BERNARDE, P. S. \& MIRANDA, D. B. Activity, habitat use, and behavior of the Bothriopsis bilineatus and of the Bothrops atrox (Serpentes: Viperidae) in Moa river forest, Acre - Brazil. Biota Neotrop., 9(3): http://www.biotaneotropica.org.br/v9n3/en/abstract?article+bn03909032009, 2009.

VIDAL, W. N.; VIDAL, M. R. R. Botânica - organografia; quadros sinóticos ilustrados de fanerógamos. 4. ed. Viçosa: Editora UFV, 2003.

VIEIRA, L. S. Manual da ciência do solo: com ênfase aos solos tropicais. São Paulo, Ed. Agronômica Ceres, 1988. 464p. 2ed. 